\title{
EVENTOS EXTREMOS NA CALHA DO RIO SOLIMÕES: UM ESTUDO DE CASO DA OCORRÊNCIA DE CHEIAS E VAZANTES NA ILHA DO CAREIRO DA VÁRZEA-AM.
}

\author{
Thayanne Lisboa Rios ${ }^{(a)}$, Jônatas de Araújo Matos ${ }^{(b)}$ \\ (a) Graduanda em Engenharia Ambiental e Sanitária (Faculdade Fucapi). E-mail: lisboa.thayanne@ @otmail.com \\ (b) Professor Mestre e orientador (Faculdade Fucapi). E-mail: jmatos.araujo@ gmail.com
}

\section{Eixo: Climatologia em diferentes níveis escalares: mudanças e variabilidades.}

\begin{abstract}
Resumo
Eventos climáticos extremos vêm se repetindo com espaço temporal muito curto na Bacia Amazônica. Cheias e vazantes na Bacia Amazônia geram impactos nas comunidades situadas às margens das planícies de inundação, por isso o enfoque da pesquisa foi dado aos eventos de cheias e vazantes e seu intervalo temporal que compreende de 2005 à 2015, dando ênfase ao evento de cheia de 2009 na Ilha do Careiro, município de Careiro da Várzea-AM, onde a pesquisa foi desenvolvida. Buscou-se realizar uma abordagem analítica acerca dos eventos de cheias e vazantes em duas comunidades no Careiro da Várzea-AM, identificando as consequências ambientais, sociais e econômicas dos fenômenos de cheias e vazantes severas às comunidades ribeirinhas do município de Careiro da Várzea (AM) e descrever os mecanismos utilizados pelos moradores das comunidades para tentar mitigar os impactos produzidos pelas cheias e vazantes. Foi realizado levantamento bibliográfico, idas a campo e trabalho de gabinete.
\end{abstract}

Palavras chave: Bacia Amazônica; Comunidade ribeirinha; Eventos extremos; Ilha do Careiro.

\section{Introdução}

Eventos climáticos extremos vêm se repetindo com espaço temporal muito curto na Bacia Amazônica. As grandes cheias e vazantes que ocorrem na Bacia Amazônia geram impactos nas comunidades ribeirinhas situadas às margens das planícies de deposição aluvionar. Nesse contexto, estudos apontam que as pesquisas devem direcionar esforços para compreender o que está resultando na ocorrência de cheias de grande magnitude. $\mathrm{O}$ enfoque da pesquisa foi dado aos eventos de cheias e vazantes e seu intervalo de recorrência em um recorte temporal que compreende os anos de 2005 à 2015, dando ênfase ao evento de cheia de 2012 na Ilha do Careiro da Várzea-AM, a maior cheia registrada na região do município. A recorrência desses fenômenos em espaço temporal muito próximo ainda gera muitas indagações devido à variabilidade hidrológica que predomina na Amazônia, e que pode ser atribuída como resultado das mudanças de comportamento climático em combinação com as ações antropogênicas que contribuem para mudanças no comportamento climático na Amazônia. 
XVII Simpósio Brasileiro de Geografia Fisica Aplicada

I Congresso Nacional de Geografia Física
OS DESAFIOS DA GEOGRAFIA FÍSICA NA FRONTEIRA DO CONHECIMENTO

Instituto de Geociências - Unicamp

Campinas - SP

28 de Junho à 02 de Julho de 2017

\section{2. Área de estudo}

A pesquisa foi desenvolvida na Ilha do Careiro, município de Careiro da Várzea-AM, onde há a presença de diversas comunidades ribeirinhas ao longo das faixas marginais, denominadas paranás devido à configuração do curso fluvial, que circunda a Ilha do Careiro da montante até à jusante.

O Careiro da Várzea é um município do Estado do Amazonas e está localizado a 22,80 km do porto de Manaus e 14,44 km do porto do Ceasa até a sede do município. As duas comunidades estão a 32,45 km do porto de Manaus e 24,21 km do porto do Ceasa até as duas comunidades.

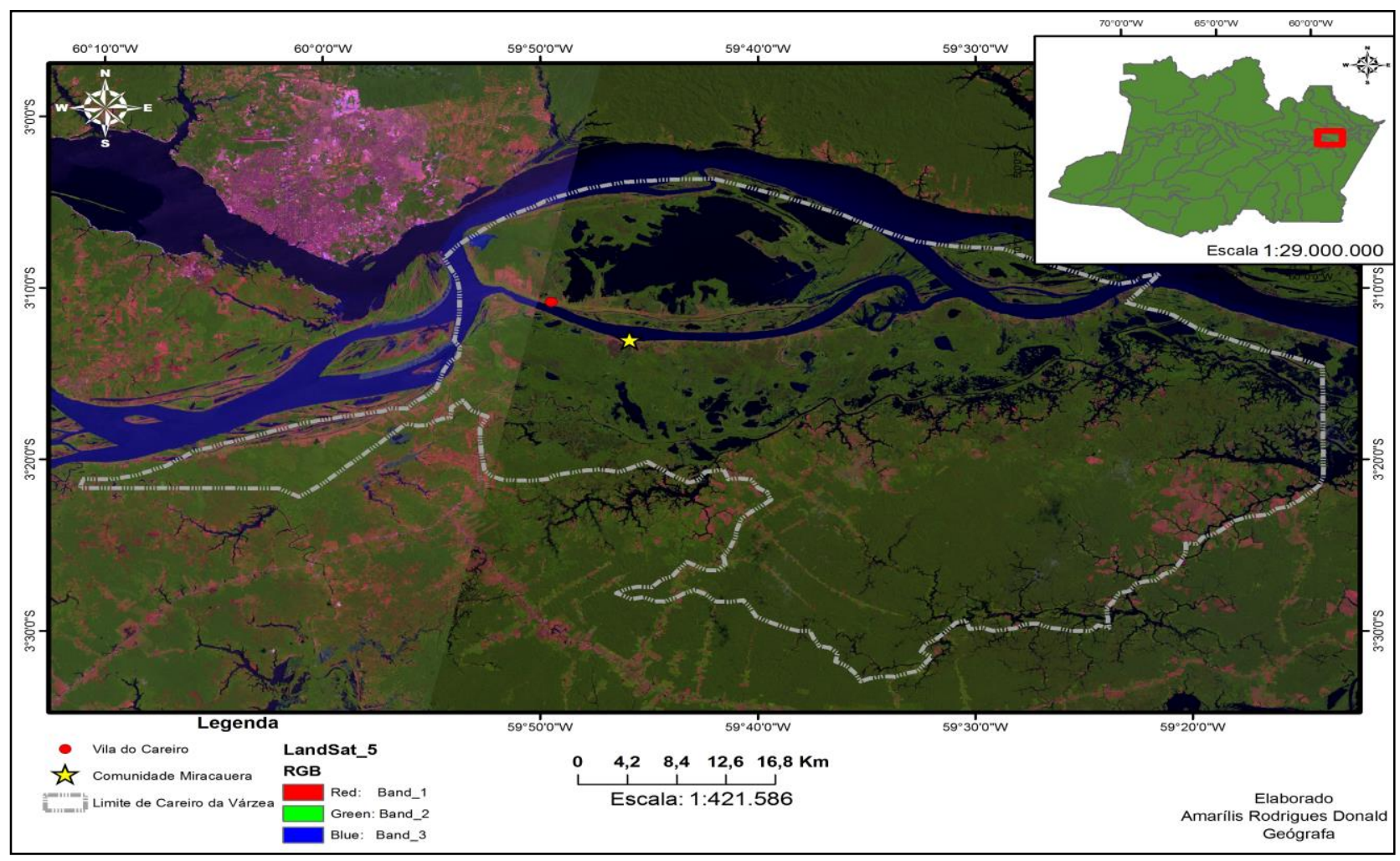

Figura 1: Área core da pesquisa.

Fonte: MATOS, J.A (2014)

O aspecto geomorfológico da área de estudo compreende duas unidades geomorfológicas distintas:

1 - Planície de bancos e meandros atuais - corresponde à faixa de sedimentos arenosos que o rio deposita através de migração lateral, ao sul e ao norte do canal durante a fase atual (...). 2 - Depósito de inundação, áreas planas e homogêneas, com lagos e tamanhos diversos e canais irregulares muito pequenos, frequentemente colmatados. (IRIONDO, 1982, p.329).

Possuindo 23.930 habitantes (IBGE, 2010) e uma estimativa populacional de 28.592 pessoas para 2016 (IBGE, 2016), a distribuição da população do Careiro da Várzea está em sua maioria na área rural, sendo 
22.930 residentes na zona rural e 1.000 residentes na área urbana, com uma densidade demográfica de $9,09 \mathrm{hab} / \mathrm{km}^{2}$ em uma unidade territorial de $2631.144 \mathrm{~km}^{2}$.

A produção econômica no Careiro da Várzea tem como principais atividades a pecuária e a agricultura, esta produção é decorrente das atividades das famílias residentes na área rural, e são as mais atingidas durante o período de cheia, pois perdem toda a sua produção de hortaliças.

\subsection{A várzea do Careiro}

Na região do Careiro da Várzea predomina a presença de planícies aluviais. A planície de inundação fluvial de deposição Holocênica, situada às margens dos rios de águas brancas na Bacia Amazônica, sujeita a inundações sazonais por se tratar de uma faixa marginal com altimetria muito baixa, portanto estando susceptível às inundações fluviais periódicas, é regionalmente, denominada várzea, cujo processo de pedogênese no ambiente de várzea desenvolvem-se sobre sedimentos Holocênicos, recentemente depositados.

Conforme Lima (2001) apud Lima et al (2007) “o nível elevado do lençol freático e a inundação periódica a que estão sujeitos limitam o processo pedogenético, resultando em solos jovens e, em alguns casos, apenas sedimentos em processo incipiente de pedogênese (LIMA, 2001, apud LIMA, et al, 2007).

No Careiro da Várzea, quanto à Geologia ocorrem dois tipos de litologias: Os aluviões, que têm sua origem no Holoceno e correspondem aos depósitos recentes e atuais das planícies fluviais e flúviolacustres e a formação Solimões, datada do Pleistoceno [...] (DNPM, 1976 a 1978, apud SAUSEN \& AQUINO s/d).

De acordo com Sternberg (1998, p.1) “a planície amazônica contém duas ordens de paisagens inteiramente diferentes: as várzeas e as terras-firmes". Conforme Cruz (2009, p.143) "ambas são complementares $[. .$.$] " e apresentam características peculiares que distinguem-se uma da outra de forma$ significativa.

Segundo o Novo Dicionário geológico-geomorfológico (GUERRA \& GUERRA, 2011, p.633) as várzeas são "terrenos baixos e mais ou menos planos que se encontram juntos às margens dos rios". Na linguagem geomorfológica é o leito maior dos rios, e recebe constantemente depósitos sedimentares.

Essa formação geomorfológica é comum nos rios que margeiam o Rio Solimões, dessa forma constituindo uma das maiores porções de terras férteis na região Amazônica, favorecendo o uso e ocupação do solo e o desenvolvimento modos de vida particulares à região.

$\mathrm{O}$ ambiente de várzea é produtos dos rios, principalmente daqueles que transportam grandes cargas sedimentares em suspensão. Estes rios inicialmente escavaram seus leitos e posteriormente depositaram seus sedimentos nos vales que deram origem à pedogênese. 
Dessa forma a várzea é resultado do acúmulo de aluviões holocênicos recentemente depositados, essa planície constantemente é recoberta pelas águas dos rios barrentos que compõem o complexo SolimõesAmazonas. Esses rios depositam grande quantidade de sedimentos em suspensão nos diques marginais, constituindo a formação de novas terras mudando a configuração da paisagem de várzea.

De acordo com Palmieri \& Larach (2011, p.109) "estas paisagens compreendem extensos domínios das planícies fluviais e fluviolacustres e distribuem-se por todo o Brasil, [...], a vegetação natural pode ser constituída por florestas e/ou campos de várzea com espécies tolerantes a excesso de água (hidrófilas e higrófilas) e com fitofisionomia de aspecto perenifólio".

\section{Objetivo geral}

Realizar uma abordagem analítica acerca dos eventos de cheias e vazantes em duas comunidades no Careiro da Várzea-AM.

\subsection{Objetivos específicos}

a) Identificar as consequências ambientais, sociais e econômicas dos fenômenos de cheias e vazantes severas às comunidades ribeirinhas do município de Careiro da Várzea (AM).

b) Descrever os mecanismos utilizados pelos moradores das comunidades para tentar mitigar os impactos produzidos pelas cheias e vazantes.

\section{Metodologia}

A pesquisa foi estruturada em quatro etapas:

a) levantamento bibliográfico e também obtenção de informações acerca da área de estudo;

b) idas a campo (o que nos permitiu realizar registros fotográficos para estabelecer um estudo comparativo);

c) trabalho de gabinete;

d) análise dos dados coletados e elaboração do artigo.

O trabalho de campo foi caráter investigativo e exploratório, sendo possível realizar o reconhecimento da área de estudo bem como as observações diretas in loco.

A segunda ida a campo também foi de caráter exploratório cujo objetivo foi identificar os problemas socioambientais causados pelas cheias nas comunidades onde foram feitos registros fotográficos nas duas comunidades (Miracauera e São João Batista). 


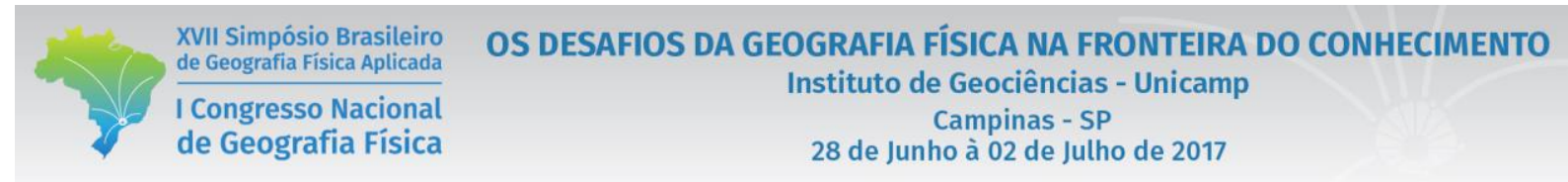

A partir das visitas frequentes nas duas comunidades em estudo foi possível perceber os mecanismos elaborados ao longo do tempo pelos moradores das comunidades estudadas. As técnicas de cultivo, construção das moradias e o modo de vida serão descritos nos resultados do trabalho.

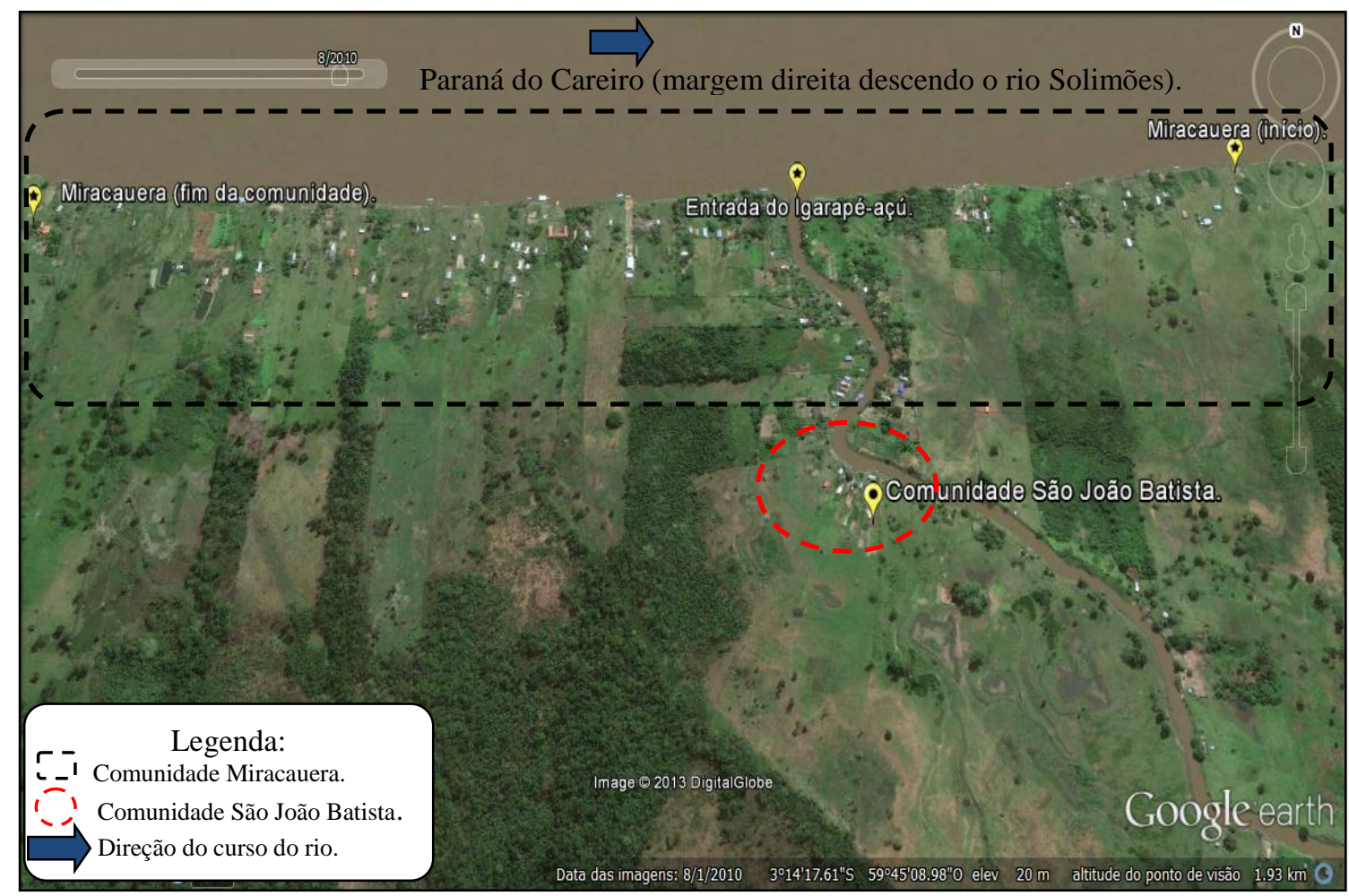

Figura 2: Área core da comunidade Miracauera.

Fonte: MATOS, J.A (2014).

As duas comunidades foram escolhidas por estarem localizadas em ambiente de várzea, onde uma delas compreende a faixa marginal no paraná do Careiro, margem direita (descendo o rio) e a outra comunidade está inserida no interior de um furo denominado igarapé-açu.

Dessa forma, o pulso de inundação atinge os moradores situados à margem do rio cuja propagação do período que compreende a inundação na várzea ocorre mais rapidamente na parte frontal próxima aos rios, nas restingas fluviais.

A propagação da cheia quando a mesma alcança o seu nível máximo de transbordamento do dique marginal é muito rápida em locais de planície, especialmente no Careiro da Várzea onde $90 \%$ da estrutura geomorfológica é constituída de ambiente de várzea. 


\section{Resultados}

Identificou-se na pesquisa a partir dos resultados obtidos que a cheia de 2012 apresentou um padrão de anomalia em relação ao período de subida do nível de flutuação da água que compreendeu a cheia de 2009. A anomalia se deu a partir do período em que começou a subida na água. De acordo com Valle et al (s/d) "o ano de 2009 se mostrou atípico do ponto de vista hidrológico em relação ao período e intensidade de cheia climatológica de alguns dos principais rios da Bacia Amazônica".

Durante a pesquisa de campo realizada em 2013 para o mestrado, cuja base de dados observacionais foi obtida a partir de observações e registros fotográficos datados de 2009 à 2014, ficou evidente no estudo comparativo que o período de subida da cheia de 2012 começou a partir de um nível considerado normal para o denominado pulso de inundação.

Entretanto, durante o mês de março, passou as cotas de 2009 (figura 3), o que gerou impactos significativos nas duas comunidades, tendo em vista que o período de permanência da cheia foi longo, comprometendo a renda da comunidade.

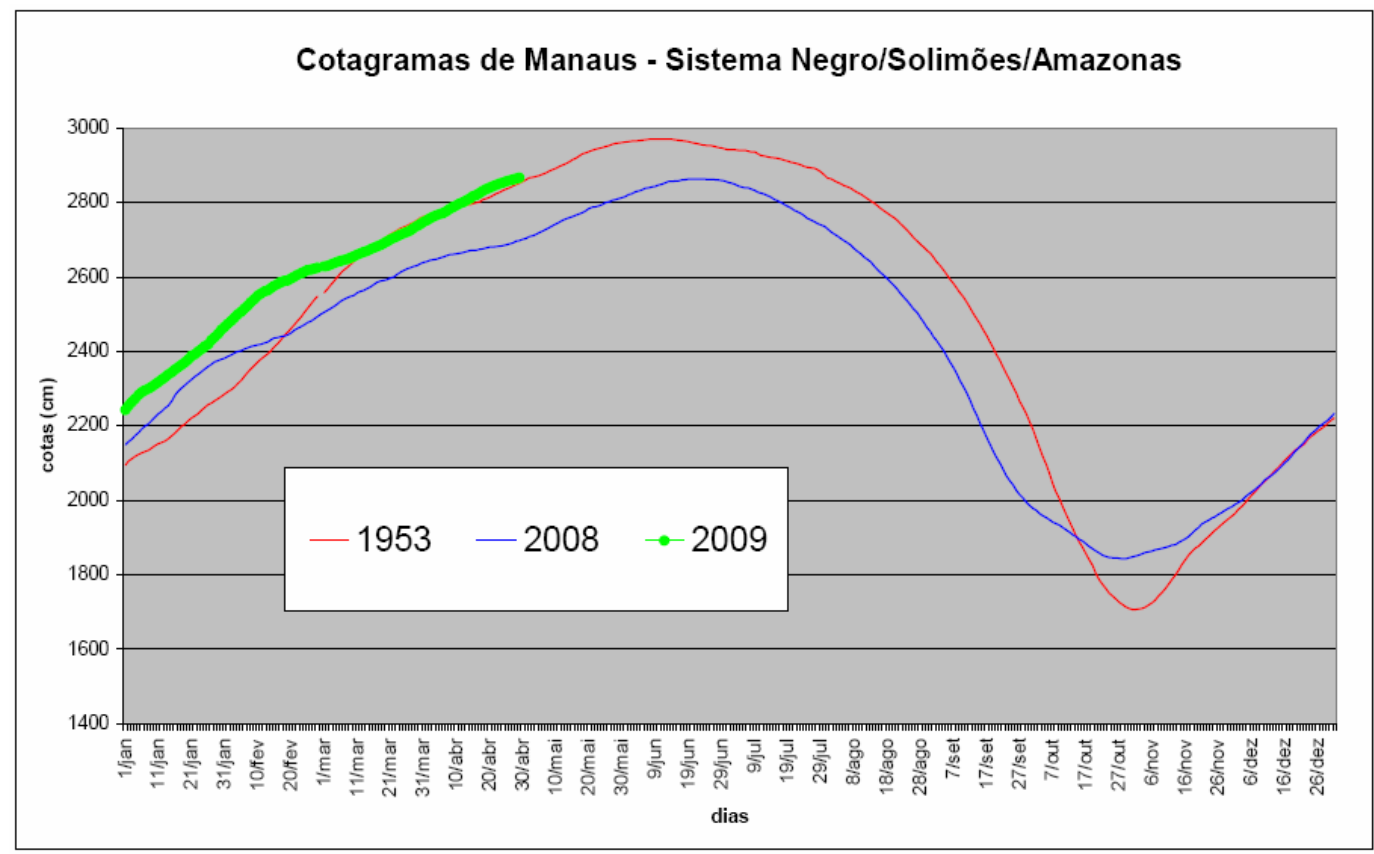

Figura 3 - Cotagrama de cheias de 1953 a 2009. Fonte: CPRM (2012).

Identificou-se na investigação científica os problemas causados pela cheia de 2012 aos moradores da várzea do Careiro. Notou-se que além dos problemas de moradias, onde os moradores migram de forma temporária uma vez que suas casas permanecem inundadas pela cheia, sendo necesário em alguns casos adaptar as moradias de modo a permitir a permanência da família, a cheia também atinge as atividades 


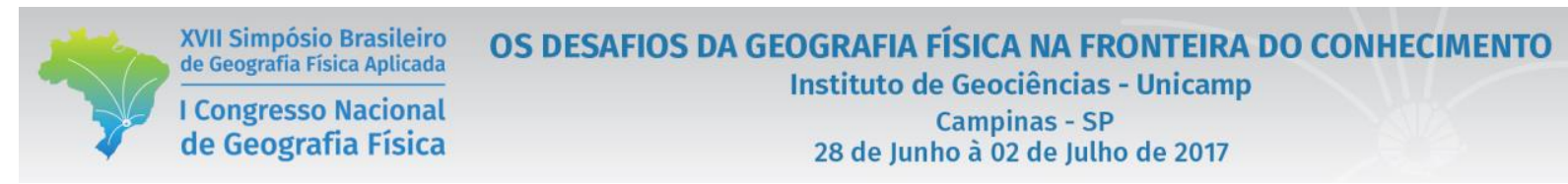

econômicas no Careiro da Várzea, gerando perdas e danos nas principais atividades econômicas: agricultura e pecuária.

Nesse ambiente sujeito às transformações que ocorrem devido à dinâmica do ambiente, as soluções encontradas pelos moradores refletem também na construção das moradias, estas revelam o desenvolvimento de uma arquitetura ribeirinha. As moradias (casas) na várzea do Careiro da Várzea possuem estilo arquitetônico peculiar.

Os ribeirinho da várzea convive com os períodos sazonais obtendo experiências do lugar, dessa forma o mesmo constrói sua casa suspensa sobre esteios (em forma de palafitas) oferecendo proteção para a família no período da cheia (figura 4), que geralmente tem duração de até 4 meses.

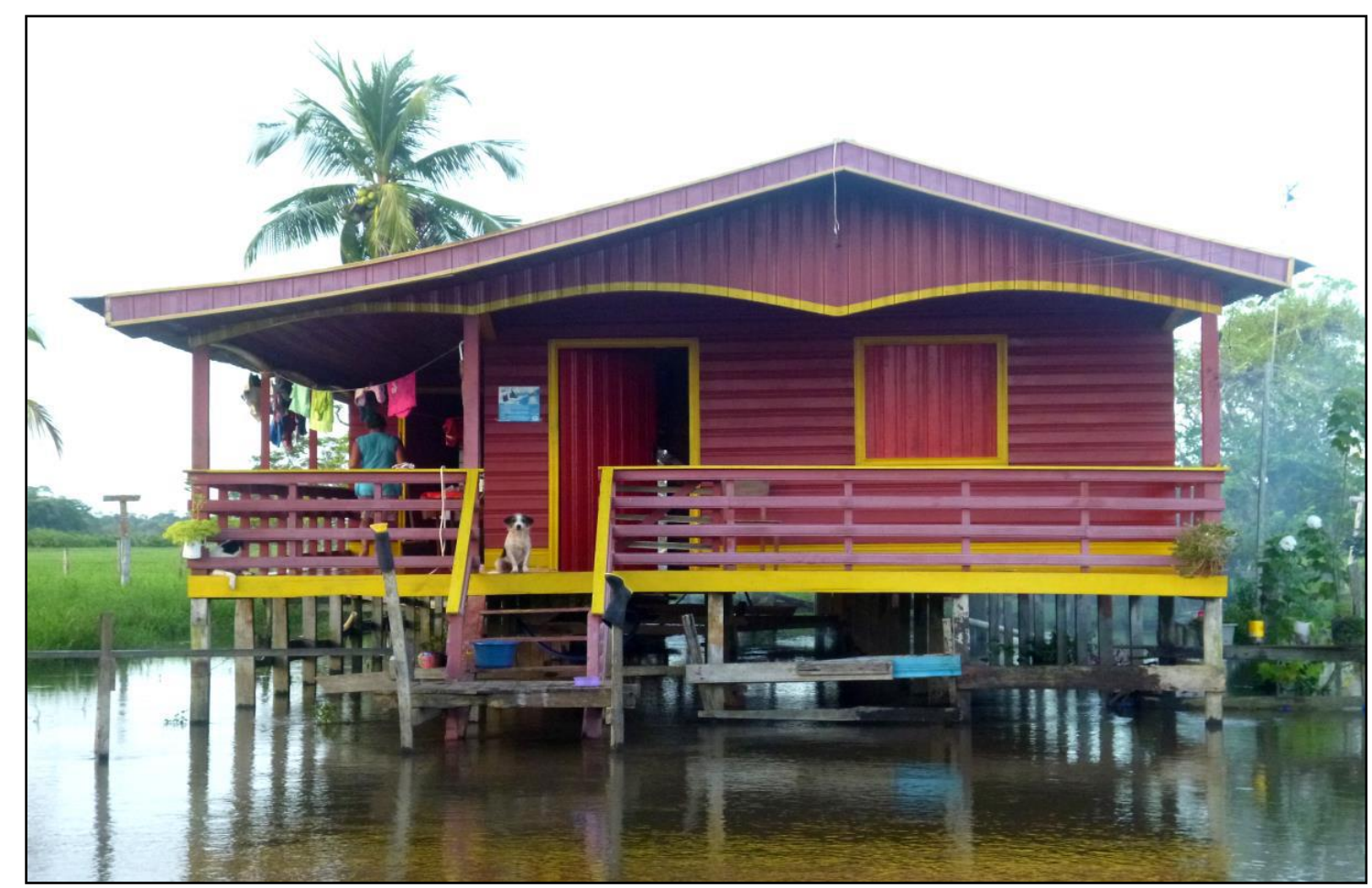

Figura 4 - Moradia ribeirinha.

Fonte: MATOS, J.A (2014).

As casas são construídas bem elevadas acima do solo, erguem-se as casas em altas palafitas, modalidade comum na Região Amazônica, que exigem assoalho durável e firme sustentado sobre esteios de madeira, que compõem a estrutura da casa do ribeirinho. 


\begin{tabular}{|c|c|}
\hline $\begin{array}{l}\text { XVII Simpósio Brasileiro } \\
\text { de Geografia Fisica Aplicada } \\
\end{array}$ & $\begin{array}{l}\text { OS DESAFIOS DA GEOGRAFIA FÍSICA NA FRONTEIRA DO CONHECIMENTO } \\
\text { Instituto de Geociências - Unicamp }\end{array}$ \\
\hline $\begin{array}{l}\text { I Congresso Nacional } \\
\text { de Geografia Física }\end{array}$ & $\begin{array}{c}\text { Campinas - SP } \\
28 \text { de Junho à } 02 \text { de Julho de } 2017\end{array}$ \\
\hline
\end{tabular}

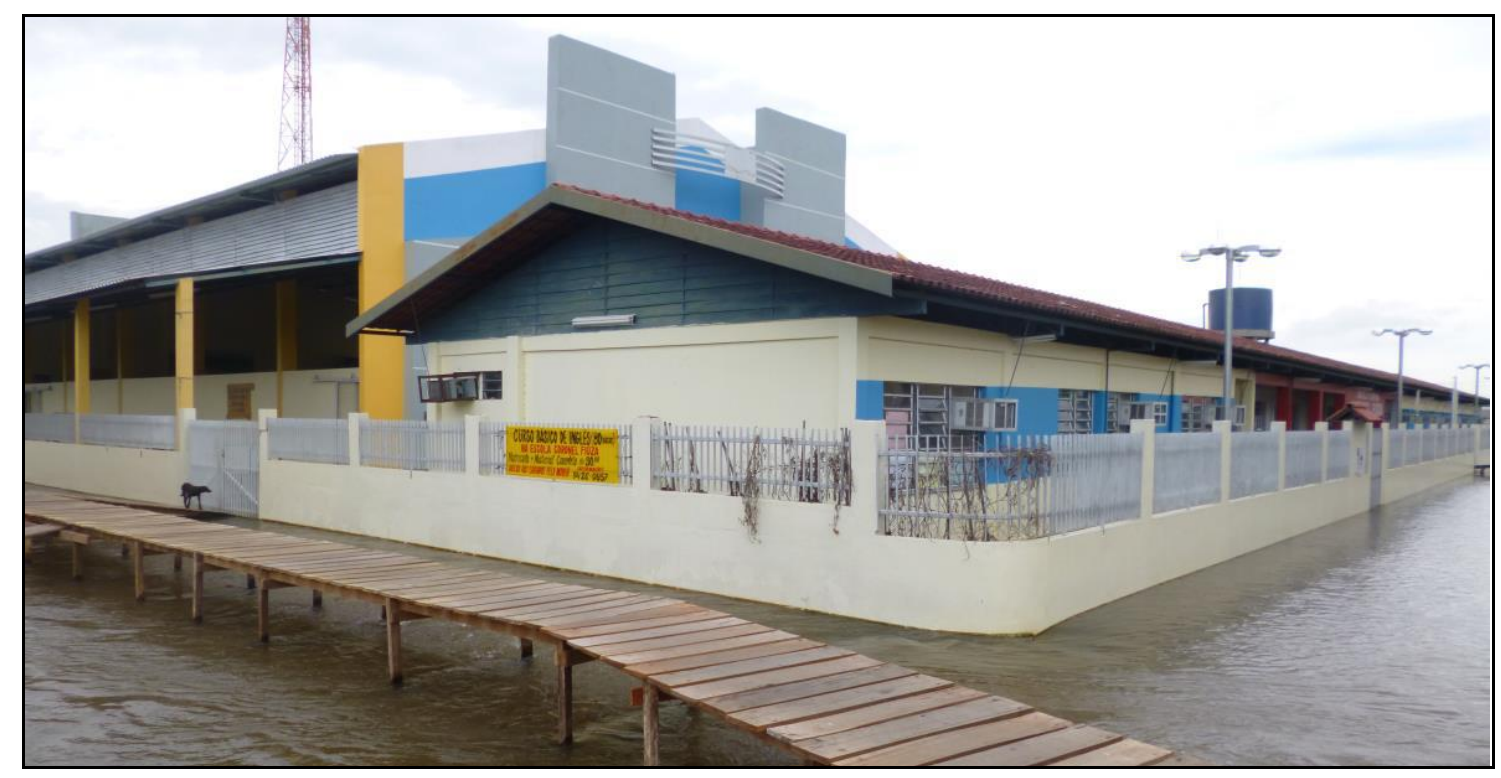

Figura 5 - Ponte ao lado da Escola Estadual Coronel Fiúza. Fonte: MATOS, J.A (2013).

A única atividade econômica que ainda sustenta durante a cheia é o serviço público, porém, a cheia afeta também o calendário das atividades escolares que é condicionado ao perído de cheia. A cheia muda a dinâmica de mobilidade no município, e como medida mitigadora são construídas pontes (figura 5) na sede municipal de modo a permitir a mobilidade das pessoas na área urbana do município (figura 6).

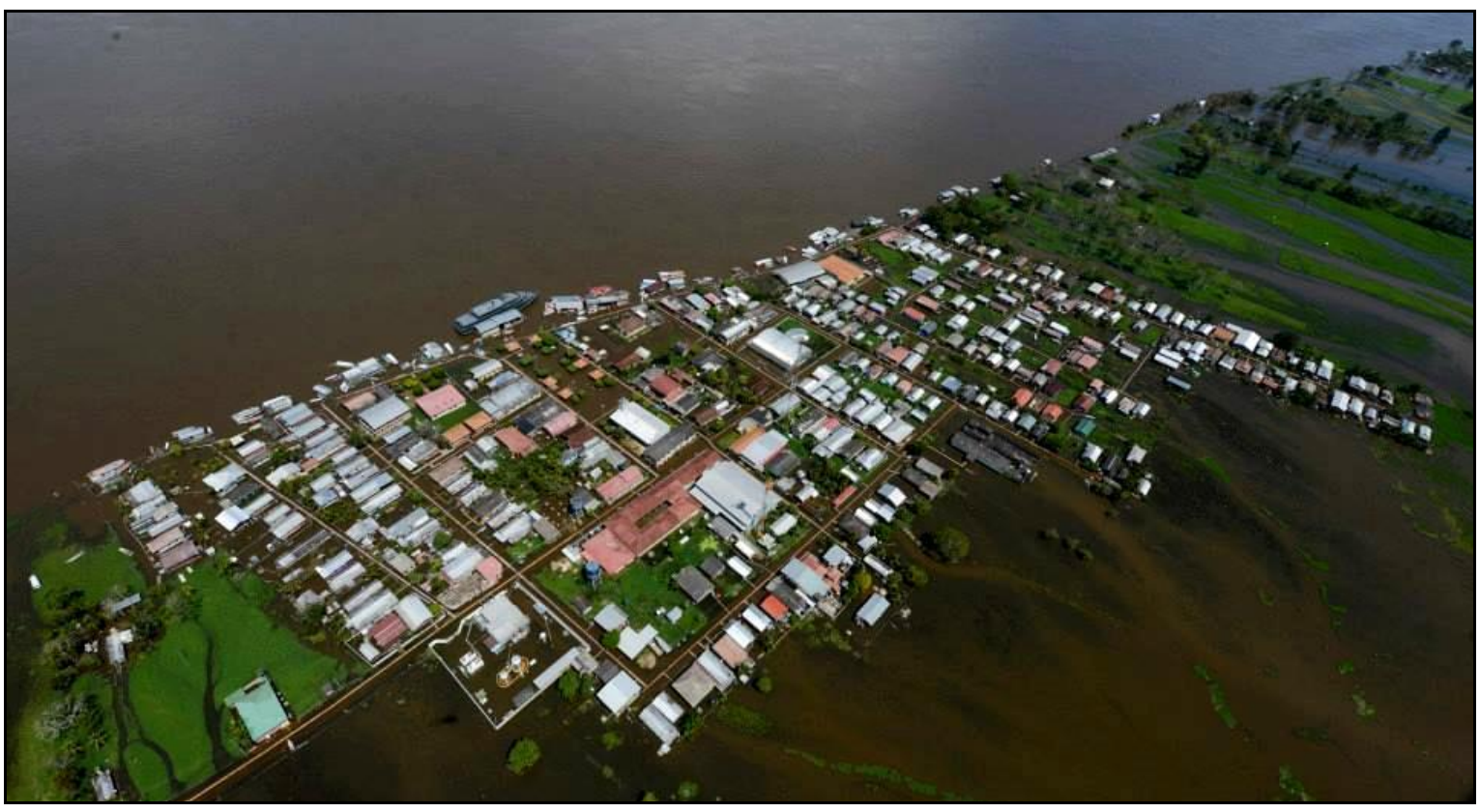

Figura 6 - A sede do município completamente inundada. Autor: Chico Batata (Junho de 2013). 


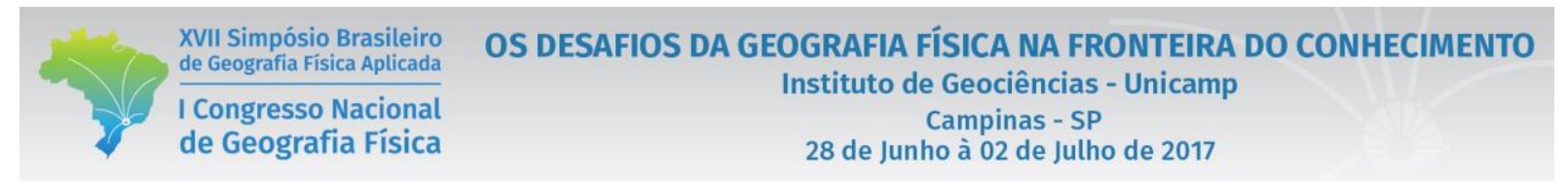

Por outro lado, o fenômeno da vazante também acarreta alguns problemas, principalmente na comunidade São João Batista, uma vez que a comunidade fica localizada em um furo chamado de igarapé-açu, o que compromete o abastecimento de água potável, haja vista que a potabilidade da água que fica retida no interior do furo é considerada imprópria ao consumo humano. Abaixo a figura (7) representa os níveis de vazante no sistema Negro-Amazonas.

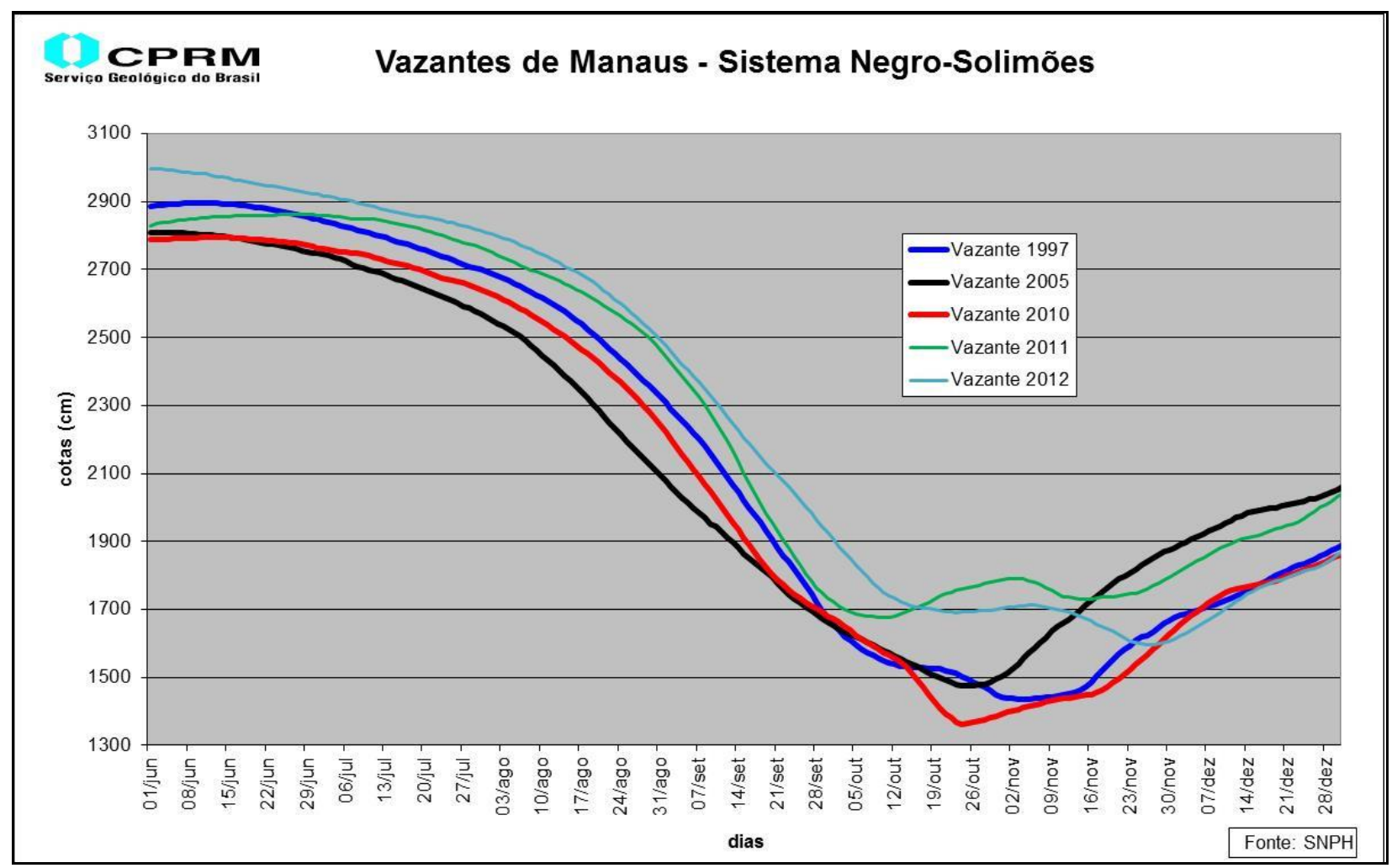

Figura 7 - Cotagrama de vazantes no espaço temporal 1997 a 2012.

Fonte: SNPH (Sociedade de Navegação, Portos e Hidrovias).

Nota-se que a vazante de 2010 no mês de outubro obteve uma cota muito baixa no período, que perdurou até o final do mês de novembro, quando o nível da água voltou a subir. As vazantes de 2010 e 2005 respectivamente, no período de outubro até novembro apresentaram cota baixa, muito semelhante para o padrão apresentado para o período. Vale ressaltar que nos anos citados, a atuação do El Niño era presente na região amazônica, o que gerou um longo período de estiagem na bacia, havendo portanto, débito de precipitações na região.

Os moradores da Ilha do Careiro anualmente são atingidos pelos dois fenômenos (cheia e vazante), o que faz com que a população do município estabeleçam mecanismos para enfrentar esses dois extremos, uma vez que o espaço de recorrência entre os eventos extremos apresentaram uma redução no intervalo de 
ocorrência, gerando problemas principalmente nos cultivos agrícolas cujo ciclo de crescimento demanda um tempo maior, dessa maneira, comprometendo a questão econômica dos moradores da comunidade.

\section{Considerações finais.}

As condições climáticas no Amazonas vêm passando por alterações no comportamento climpático, que influencia diretamente na hidrologia da região, gerando eventos extremos de cheias e vazantes que impactam os moradores nas comunidades ribeirinhas.

Embora tenham enfrentado uma grande vazante em 2005 e outra em 2010 e três enchentes $(2009,2011$ e 2012) com espaço temporal muito próximo, os moradores das comunidades estudadas sentem os reflexos das dificuldades de plantar seus cultivos, realizar a irrigação do plantio, já que dependem do regime hidrológico. Este por sua vez vem apresentando mudanças no que se refere ao processo de subida e descida do nível do rio.

Mesmo sendo submetidos anualmente a esses fenômenos, os moradores das duas comunidades estudadas, desempenham um modo de vida condicionados pela atividade fluvial, como destaca Tocantins (2000) "o rio comanda a vida".

Sternberg (1998) em seu estudo sobre "A água e o homem na várzea do Careiro" chama atenção para a dependência entre as populações ribeirinhas e os cursos d'água. Sternberg investigou também as consequências dessa relação para os rios, que se tornam graves quando o desmatamento aumenta o fluxo de água e reduz a calha dos rios por acúmulo de sedimentos, causando enchentes que afetam as comunidades que vivem às suas margens.

É o subir e descer da águas na várzea careirense que modela a paisagem na várzea, e desta forma, produz novas paisagens, e com os eventos de cheias e vazantes periódicas, faz com que os moradores das margens dos rios estabeleçam um modo de vida de acordo com a sazonalidade fluvial.

Os cultivos, a criação de rebanho bovino, as atividades diárias, todo o cotidiano recebe influência do rio. As condições climáticas na região possibilitam altos índices pluviométricos na bacia amazônica, entretanto, devido às mudanças no commportamento climático, vem afetando a região com eventos extremos pronunciados.

Nesse sentido a ilha do Careiro é uma das regiões mais afetadas em ambos os perídos, seja na cheia ou na vazante, considerando que a topografia do Careiro da Várzea compreende uma região de várzea baixa, permite a propagação da cheia com maior volume.

As condições naturais do Careiro da Várzea e suas características de relevo conferem um modo de vida peculiar, pois a população que habita nesse município vivenciam as limitações e potencialidades desse 


\section{OS DESAFIOS DA GEOGRAFIA FÍSICA NA FRONTEIRA DO CONHECIMENTO \\ Instituto de Geociências - Unicamp \\ Campinas - SP \\ 28 de Junho à 02 de Julho de 2017}

ambiente de várzea e se mantém no lugar observando a dinâmica existente e desenvolvendo mecanismos a partir da percepção para o desenvolvimento de suas atividades tanto no período das águas baixas ou durante a cheia.

Essas características, com predominância de planícies de inundação, estabelecem uma dinâmica que com frequência muda os hábitos dos moradores das comunidades por um período que varia de 2 até 4 meses, compreendendo o período da enchente.

Durante esse período, os moradores da comunidade estão sujeitos ao regime das águas, todavia essa relação demonstra que o morador tem relações com o lugar que os fortalecem, apesar das mudanças periódicas que essa dinâmica promove no ambiente durante a cheia e depois da mesma.

Essas mudanças ocasionam alterações no cotidiano dos moradores do município, que precisam construir pontes para possibilitar o acesso aos domicílios e o deslocamento das pessoas na área urbana do município e também na área rural nas comunidades.

É comum para as pessoas o deslocamento em canoas, todavia, no período de inundação fluvial, as canoas se tornam indispensáveis na manutenção do cotidiano das pessoas e principalmente, as relações sociais dos moradores e o desenvolvimento das atividades econômicas, embora esta seja afetada de forma significativa, reduzindo o rendimento dos comerciantes e concomitante a geração de renda dos moradores nas comunidades, pois nesse período o cultivo reduz em $80 \%$.

O deslocamento via terrestre e o desenvolvimento de outras atividades também é comprometido, um exemplo disso são as aulas que são suspensas em todo o município e posteriormente são retomadas com calendário especial após o período de cheia, dessa forma evita-se a exposição dos alunos a riscos de acidentes, pois os mesmos se deslocam de comunidades distantes e só chegam em suas casas no período noturno.

A diretora da Escola Estadual Coronel Fiúza (em 2012) relatou que foram registrados pequenos incidentes envolvendo alunos da escola, tais como: pontes que caiam com alunos, canoas que alagavam no trajeto de casa até o porto para aguardar a condução do barco escolar. Em 2013 adotou-se medidas preventivas para evitar acidentes, os alunos eram liberados mais cedo, pois o município estava totalmente inundado.

Conforme Nogueira (2001, p.13) "é interessante ver primeiramente os lugares com olhar de quem nele habita e a partir daí olhar o mundo, que é construído cotidianamente nesta relação com os lugares", foi por isso que nessa investigação passamos a ouvir também os relatos dos mroadores acerca das mudanças ocorridas na várzea e saber deles como seu modo de vida era influenciado pelo regime das água. 


\section{Bibliografia.}

Companhia de Pesquisa de Recursos Minerais (CPRM). Relatório da vazante 2012 (gerenciamento da vazante Manaus evento 2012).

CUNHA, Sandra Baptista da; GUERRA, Antônio Teixeira (org.). Geomorfologia - uma atualização de bases e conceitos. Rio de Janeiro: Bertrand Brasil, 1994.

CUNHA, Sandra Baptista da; GUERRA, Antônio Teixeira. Degradação ambiental. In: Geomorfologia e meio ambiente. GUERRA, Antônio Teixeira; CUNHA, Sandra Baptista da (org.). $10^{\mathrm{a}}$ ed. Rio de Janeiro: Bertrand Brasil, 2011.

GUERRA, Antônio Teixeira. GUERRA, Antônio José Teixeira. Novo dicionário geológico-geomorfológico. $9^{\mathrm{a}}$ edição. Rio de Janeiro: Bertrand Brasil, 2011.

Instituto Brasileiro de Geografia e Estatística. Síntese do município. Disponível em <http://cidades.ibge.gov.br/v3/cidades/municipio/1301159> acessado em 13/02/2017.

LIMA, H.N; TEIXEIRA, W.G; SOUZA, K W de. Os solos da paisagem de várzea com ênfase no trecho entre Coari e Manaus. In: Comunidades Ribeirinhas amazônicas: modos de vida e uso dos recursos naturais. EDUA, 2007.

MATOS, Jônatas de Araújo. CURSINO, Alcirene Maria da Silva. Caracterização geomorfológica das "terrascaídas” em área de várzea na comunidade Miracauera, Careiro da Várzea-AM. In: Revista Geonorte, Edição Especial, V.1, No 4, p.515-525, 2012.

NOGUEIRA, Amélia Regina Batista. Percepção e representação gráfica: a "Geograficidade" nos mapas mentais dos comandantes de embarcações no Amazonas. Tese de doutorado. USP, São Paulo, 2001.

PALMIERI, Francesco. LARACH, Jorge Olmos Iturri. Pedologia e Geomorfologia. In: Geomorfologia e meio ambiente. GUERRA, Antônio Teixeira; CUNHA, Sandra Baptista da (org.). 10ª ed. Rio de Janeiro: Bertrand Brasil, 2011.

SOARES, L.C. de. Hidrografia. In: Fundação Instituto Brasileiro de Geografia e Estatística (IBGE), Geografia do Brasil, Região Norte, Rio de Janeiro, 1977.

STERNBERG, Hilgard O'Reilly. A água e o homem na várzea do Careiro. 2. ${ }^{a}$ ed. Belém: Museu Paraense Emílio Goeldi, 1998. 330 p.

TOCANTINS, Leandro. O rio comanda a vida. - uma interpretação da Amazônia. $9^{a}$ Ed. - Manaus: Editora Valer. Edições Governo do Estado, 2000.

VALES, Roseilson do; FILIZOLA, Naziano; SOUZA, Rodrigo. A cheia de 2009 na Amazônia Brasileira: uma análise preliminar. $(\mathrm{s} / \mathrm{d})$. 